\title{
The gender specifications of the emotional representation in a communication space
}

\author{
Irina Shcherbakova $^{1}$, Nadezhda Kovalchuk $^{1 *}$, Maria Timashova $^{1}$, Irina Tsarevskaya ${ }^{1}$, and \\ Julia Soprantsova ${ }^{1}$
}

${ }^{1}$ Don State Technical University, 1, Gagarin sq., Rostov on Don, 344003, Russia

\begin{abstract}
The purpose of the article is to describe the gender peculiarities of the objectification of emotions in the verbal and non-verbal aspects of the communicative behavior of female and male characters in a literary text. Of interest is the study of the features of the representation of emotions in the literary text, taking into account the factor of gender influence on the communicative behavior of a person and the choice of language means. Text fragments which most clearly described the emotional experiences and states of female and male characters were selected by a continuous sampling method from the modern literary compositions of the 20th - 21st centuries written in Russian by women and men. Features of emotion explication were analyzed taking into account gender identity in texts of literary prose. Gender preferences in the choice of language means of expressing emotions in speech were identified. The following research methods were used to achieve the objectives: a descriptive method involving analysis, comparison and classification of language facts; contextual analysis method. The practical significance of the work is the possibility of applying the main conclusions and results of the investigation in theoretical courses in linguistic studies of emotions and gender.
\end{abstract}

\section{Introduction}

The relevance of the research is mainly determined by the current development trends of anthropocentric linguistics and the increased interest in the analysis of linguistic means, the nominating phenomena of human nature, and also by the importance of a comprehensive study of means and methods of representation of emotions in art communication, namely the gender objectification of emotions in verbal and non-verbal aspects of communicative behavior of a person in a literary text. In modern linguistics, there is a relentless interest towards the emotional sphere of the individual (L. G. Babenko, N. A. Krasavsky, G. E. Kreidlin, E. Yu.Myagkova, V. I. Shakhovsky, etc.). "Everything in a person is driven by emotions, which form the motivational basis of his activity" [1]. At the present stage of development of linguistics, emotiology has been formed and is actively developing as a separate branch of linguistics, which is aimed at studying the laws of language representation of emotions.

\footnotetext{
${ }^{*}$ Corresponding author: nadezhda kovalchuk_2012@mail.ru
} 
In the Humanitarian science emotion is understood as a "mental reflection in the form of a direct biased experience of the essense of life phenomena and situations predetermined by the attitude of their objective properties to the needs of the subject [2]."; "a special class of mental processes and conditions (human and animal) that are related to instincts, needs, motives and reflecting in the form of direct experiences the importance of the phenomena and situations to carry out his life" [3]; "one of the forms of reflection of the world, denoting emotional experiences, excitement, feelings" [4]. According to E. Y. Myagkova, emotion "combines different phenomena: emotional reactions that have their analog in external ways of expression [5]; emotional states that are associated with internal emotional experience that does not have an external manifestation" [6].

In our opinion, it is relevant to study feelings and emotions in fiction. The artistic text fully reflects the emotional sphere of an individual, which makes it possible to explore various aspects of emotivity [7]. As V. I. Shakhovsky notes, "any artistic text obligatorily reproduces the emotional life of people [8]. In a literary text, emotions are observed not directly, but through specific language signs that are material, apparent, and that serve to manifest emotions [9].

According to G. V. Stepanov, "in the center of the figurative system of a work of art is the image of a person (characters and their relationships), which, in fact, is the content of the work, in which the author simulates the objective reality" [10]. Thus, the artistic text reflects the real emotional sphere of a person, which allows us to explore the features of the representation of emotions in the national language [11].

\section{Methods, techniques and technologies used}

In our work, we used various methods, including theoretical; empirical (observation, questioning).

\section{Results}

The gender approach in linguistic research is determined by the need to consider the communicative behavior of an individual in relation to cultural traditions, norms and stereotypes [12]. It is known that gender relations are fixed in the language in the form of culturally determined stereotypes, leaving an imprint on the speech behavior of the individual and on the processes of its socialization [13].

The existing stereotypical ideas about the peculiarities of the emotional sphere of women and men are fully reflected in the literary text [14]. A woman is credited with greater emotionality and sensitivity compared to a man, and a man, according to gender stereotypes, is opposed to a woman being logical, rational, and objective, which is reflected in communicative behavior [15]. For our research, it is interesting to analyze the features of the representation of emotions in a literary text, taking into account the influence of gender on the communicative behavior of an individual and the choice of language means.

The gender specifics of the representation of the emotional state of a character in a literary text is actualized by nominations that stereotypically objectify male and female expressions of emotions, which are represented by gender-marked lexical means, as well as kinetic and phonation-prosodic components. From the standpoint of semiotics, "various emotional manifestations of a person: emotional reactions, feelings, emotional states, affects, moods can be expressed by linguistic and paralinguistic means, the combination of which makes up a special sign emotive code of a particular language". Understanding communication as "an interdependent unity of verbal, non-verbal, extralinguistic and paralinguistic constituents", we consider the features of the emotional state of the character 
in the verbal and non-verbal aspects of communication. "The characters' experiences and emotions are transmitted not only verbally, but also by means of non-verbal communication, and the authors of fiction often give even more convincing descriptions of a person's emotional life than psychologists do".

Using a continuous sampling method, we selected text fragments from works of modern fiction that most vividly described the emotional experiences and states of female and male characters. A character is understood as "a series of consecutive appearances or mentions of one person; an image of his words, actions, external features, internal states, a narrative about events related to him, an author's analysis". This study analyzes fragments of two "subject speech spheres": character and non-character speech.

The main means of describing the emotional state of a woman's character and a man's character in a literary text include direct nominations of emotions and lexical means of expressing emotions, i.e. indirect designation of the emotional state of communicants through the description of appearance, facial expressions and behavior. Thus, in a literary text, emotions are objectified by naming, indicating, describing lexical units, as well as various constructions to enhance the expression of the character's emotional state.

Gender stereotypes, social roles of men and women, their behavior patterns, as well as the asymmetry of social relations between men and women are reflected in their speech behavior. As the analysis of practical material has shown, the specifics of male speech behavior is distinguished by a tendency to specificity and logic, the predominance of direct nomination of emotions, and the rare use of descriptive constructions. For example: You are a bastard! I hate you! I wish you were dead! [Alexey Slapovsky. Death of the guitarist].

The existing stereotype of a male behavior affects the features of emotional communicative behavior, which is manifested in minimizing the demonstration of emotions. For example: What I don't care about, and I don't care about everything except those few things that I do care about, and that - just to the extent of indifference - I am really immoral. [Anatoly Naiman. Love interest].

A typical male way of expressing negative emotions is to use rude language, for example: do you think I could do anything?! I couldn't fucking do it! Here! [Viktor Remizov. Volya Volnaya].

Also: What a bitch! the kitchen boy swore without malice and, turning to Zhebrovsky and pointing a finger at uncle Sasha, added: "he's my Kolka's godfather [Viktor Remizov. Volya Volnaya].

The descriptive style of communication prevails in the communicative behavior pattern of the female character. In contrast to a man, a woman describes her feelings and experiences, but does not name the reason. For example: My God, how incomprehensible and all-powerful, how fiercely inexhaustible the generosity of this unique world which is like you is, my love - but why this menacing, inexorable, ever-increasing noise, this icy, never-abating wind? [Marina Paley. Long Distance, or Slavic accent].

Female speech is characterized by hyperbolized expression. In the verbalization of emotions in women's speech, interjections that express emotions, feelings, and experiences (Ah!, Oh!; Uh! Oops!); suffixes of subjective evaluation (red, striped, nice), vocabulary with evaluation semantics are revealed. For example: She laughed again, but thought suddenly: "Oh, I'm sorry, my Bunny. I'm not laughing at you, never mind. Wait, I'll brush off the powder.. [Dina Rubina. Russian Canary. Prodigal son].

Words with subjective evaluation suffixes in female speech reveal mostly positive emotions (joy, sympathy, empathy). For example: Elena put her arm around his neck: "Hush, dear... And he was still, holding her close to his chest: [Lyudmila Ulitskaya. Journey to the seventh side of the world].

The use of words with diminutive suffixes in male speech indicates a negative connotation of these words. For Example: Come On! Ca! Call him! To your hubby! He's 
probably with his Polish mistress, watching some seedy movie and licking each other! [Asya Petrova. Devil of mental].

In describing the emotional state of a man, there is a tendency towards the accuracy of the nomination of emotions, for example: all possible human expressions pass through him: contempt, anger, interest, disgust, indifference, ridicule... [Viktor Pelevin. The love for three Zuckerbrins]

In the representation of a female character's emotional state, descriptive constructions, metaphorical expressions, exaggerations, and intensifiers are more widely used. For example: Julie was running around the room, bursting with annoyance, and I thought that I would burst out laughing, but it was indecent to laugh in such a situation, so I said: "the Main thing is to remember that all this mess is not the end of the world." I shouldn't have said that - Julie had such a Nabokovian despair imprinted on her face that even Nabokovists and even, probably, Professor Averin never dreamed of [Asya Petrova. Devil of mental].

The emotional communicative behavior of a character is verbalized in the literary text by means of locutionary verbs. Direct speech is introduced by the locutionary verbs, which help to reveal the emotional state of the female and male character. Among the the locutionary verbs that introduce the direct speech of a woman, verbs with emotionally expressive semantics prevail (to gibber, to croon, to scream, to sing, to squeal, etc.). For example: - Did you freak out?! - she gibbered. - Now I'll... I'll jump out of the train, I... do not intend to listen to this heinous nonsense!.. [Dina Rubina. A few hasty words of love].

Also: Today Geisikha, wearing a tailleur and low-heeled shoes, announced that she was going to the city to buy gifts for her friend's friend, and invited me to join, because I, they say, was well-versed in cloth and perfume. "Choose your favorite seduction," she crooned. How could Humbert evade being the owner of a perfume company? [V. Nabokov. Lolita].

To describe the manner of speech of women and men, verbs of the emotional spectrum associated with emotional distress are used.

It has been established that emotions are most vividly transmitted by changing the voice (to whisper, to scream, to snarl, to squeal, to yell, to whine, etc.). The following verbs were identified as "feminine" ones to express the emotions: to squeal, to cry out. The "masculine" ones are to snarl, to croak, to speak loudly. For example: Her eyes darkened. Ah, bitch! - She squealed and poked the drunkard with her fist in the stomach [Daria Dontsova. Dollars of Tsar Gorokh].

Also: A hundred will suit? - seriously... Gena croaked with fear, feeling the most severe disappointment with the client.... Okay, - Gena wheezed, pushing the accelerator, trying not to get behind the old Volvo, that was in front. - By the way, you don't teem with money, do you? - the client sniffed [Evgeny Sukhov. When the job is done, the prison term starts].

Paralinguistic characteristics play an important role in describing the emotional state of a male and female characters. In female non-verbal speech behavior, the following prosodic components were identified as the most frequent: sobbing, crying, sighs, screaming, etc. For example: And then she was sobbing, smearing tears with her hand - there was no handkerchief in her purse - and muttering: - Who needs him, - except me? No one needs him [Marina Vishnevetskaya. The moon went out of the fog].

It should be noted that it is non-verbal characteristics in the process of communication that express "certain emotional attitude of communicants to the depicted circumstances and its assessment" [Aristov 1998, p. 27]. In the analysis of non-verbal means of representing emotions in the artistic text, the following components of non-verbal speech were highlighted: prosodics (pace, timbre, the pitch of a voice and its loudness) and kinesics (facial expressions, gestures, poses).

\section{Discussion}


The study found that when representing some emotions, such as anger, rage, fear, women and men show the same kinetic (facial expressions and gestures) components of non-verbal behavior. We will demonstrate gender peculiarities in non-verbal speech behavior of women and men using the example of representation of such emotional state as surprise in a literary text. When describing the emotion of surprise in female nonverbal behavior, attention is focused on parts of the face such as the forehead and eyebrows. For example: No! - the housekeeper raised her eyebrows in surprise. - Five cars can be parked here [Daria Dontsova. Goldfish soup].

The emotional state of surprise for men is revealed using lexical units describing the eyes, face, head and body movements. For example: Grym's face fell, he was surprised and I realized that he was no longer looking at Hennelora, but somewhere up and away [Victor Pelevin. S.N.U.F.F].

The peculiarities of the expression of male and female emotions depend more on the emotion itself and the degree of intensity of its demonstration. For example, such emotions as anger, indignation, shame are accompanied by changes in the color of the face, breathing; emotion of fear - in trembling of hands; emotion of surprise is associated with eyes, eyebrows, etc. Each emotion is distinguished by its specific means of non-verbal communication.

\section{Conclusion}

The analysis of objectificational peculiarities of emotions in the verbal and non-verbal aspects of the communicative behavior of female and male characters in a literary text, taking into account the gender of both the author and the character, made it possible to come to the following conclusions:

1. As a result of a continuous sample, the most frequent emotional states of a female and male character in the texts of modern literary prose were selected: joy, sympathy, surprise, anger, hatred, fear, sadness, grievance, contempt, disgust, shame.

2. 1840 contexts, 913 lexical units were analyzed.

3. It has been established that the dominant emotions for female communicative behavior are those of joy $(31.4 \%)$, fear $(21.6 \%)$, shame $(17.3 \%)$, hatred (16\%), sadness $(11.4 \%)$, and sympathy $(7.5 \%)$.

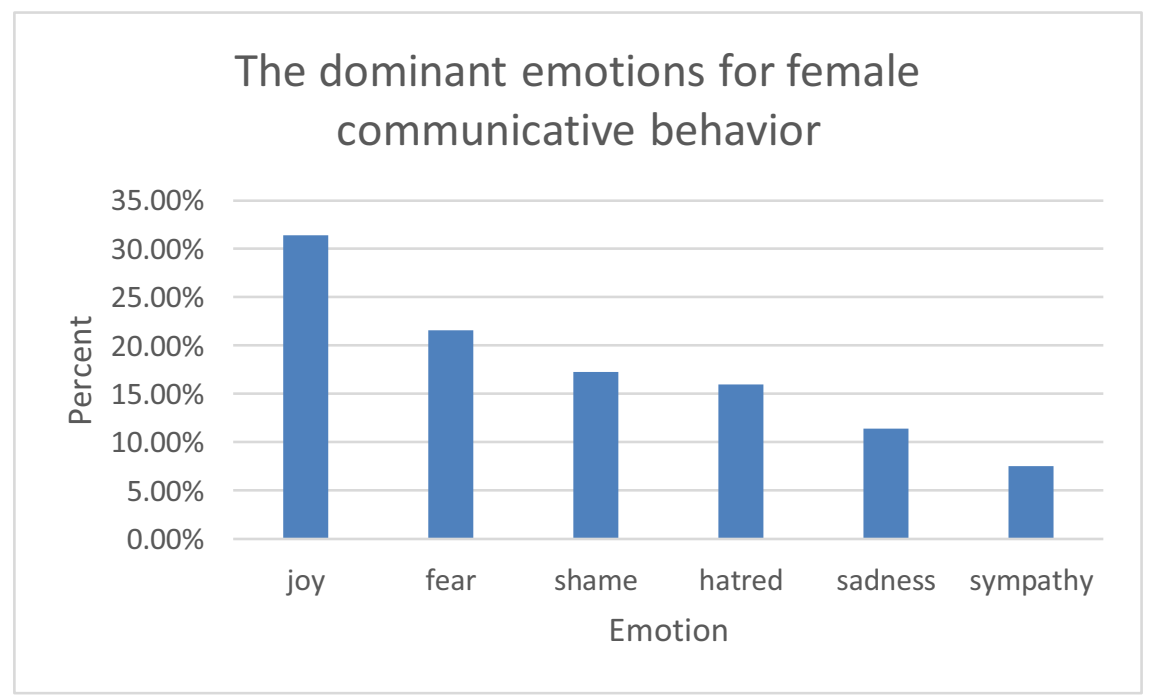

Fig. 1. The dominant emotions for female communicative behavior. 
4. For male - anger (35.2\%), wroth (29.1\%), surprise (25\%), indifference $(22.1 \%)$, delight $(13.7 \%)$, pleasure $(5.9 \%)$.

\section{The dominant emotions for male communicative behavior}

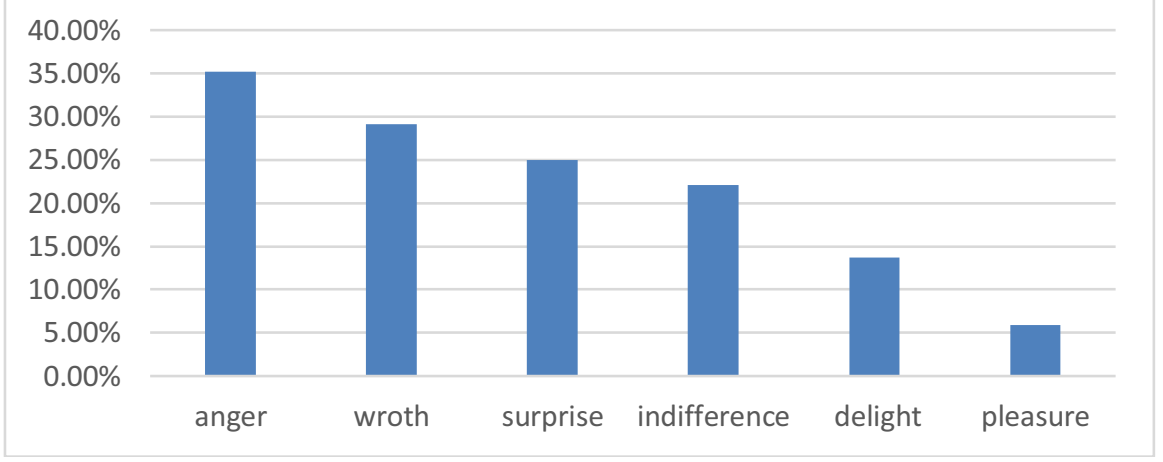

Fig. 2. The dominant emotions for male communicative behavior.

5. The emotional state of a female and male character in the verbal and non-verbal aspects of the communicative behavior is presented by means of direct nomination, description of emotions, as well as the combination of these two mechanisms.

6. Gender stereotypes of femininity and masculinity, the social roles of women and men, their behavior model, as well as the asymmetry of social relations between men and women are reflected in their communicative behavior. Thus, stereotypes of female and male behavior affect the features of emotional communicative behavior. It has been established that gender stereotypes, the social roles of men and women, as well as the asymmetry of social relations between men and women are reflected in their communicative behavior (verbal and non-verbal).

\section{References}

1. M. AbdelWahab, C. Busso, IEEE/ACM Transactions on Audio, Speech and Language Processing, 26 (12), 2423-2435 (2008)

2. A. Kotov, N. Arinkin, L. Zaidelman, A. Zinina, A. Filatov, Advances in Intelligent Systems and Computing, 636, 126-132 (2018)

3. J. Hou, C. Zhang, R.A. King, International Review on Public and Nonprofit Marketing, 15 (1), 25-47 (2018)

4. D. Oudin-Doglioni, M.-C. Gay, M.-P. Lehougre, F. Galactéros, J.-B.Arlet, Annales Medico-psychologiques, revue psychiatrique, 177 (6), 517-525 (2019)

5. E.T. Rolls, Neuropsychologia, 128, 14-43 (2019)

6. Z.R. Khachmafova, I.S. Karabulatova, S.A. Lyausheva, E.N. Luchinskaya, G.V. Osipov, Mediterranean Journal of Social Sciences, 6 (3), 476-481 (2015)

7. I.S. Karabulatova, Z.R. Khachmafova, M.M. Bricheva, T.T. Nescheretova, A.K. Bersirova, Review of European Studies, 7 (6), 35-45 (2015)

8. T.A. Ostrovskaya, Z.R. Khachmafova, S.A.Lyausheva, I.S. Karabulatova, G.V.Osipov, Mediterranean Journal of Social Sciences, 6 (3 S4), 147-154 (2015)

9. A.P. Tikhonova, S.R. Makerova, S.A.Sasina, E.N. Orekhova, Z.R. Khachmafova. 
Mediterranean Journal of Social Sciences, 6 (3 S4), 115-120 (2015)

10. Z.R. Khachmafova, I.S. Karabulatova, S.V. Serebriakova, A.V. Zinkovskaya, E.N. Ermakova. Pertanika Journal of Social Sciences and Humanities, 25 (July), 137-150 (2017)

11. I.S. Karabulatova, S.A. Lyausheva, Z.R. Khachmafova, I.P. Savchuk, O.S. Shibkova, Astra Salvensis, 6 (12), 737-744 (2018)

12. A.V. Olyanitch, Z.R. Khachmafova, S.R. Makerova, M.P. Akhidzhakova, T.A. Ostrovskaya, 1084, 109-121 (2019)

13. A.V. Olyanitch, Z.R. Khachmafova, S.R. Makerova, M.P. Akhidzhakova, T.A. Ostrovskaya, Lecture Notes in Networks and Systems, 87, 442-448 (2020)

14. A.V. Olyanitch, M.P. Akhidzhakova, Z.R. Khachmafova, B.N. Akhidzhak, E.A. Gashimov, Lecture Notes in Networks and Systems, 129 LNNS, 3-11 (2020)

15. A.A. Kalashnikova, O.M. Akay,, I.V. Tsarevskaya, M.S. Volodina, E.O. Tsybenko, Man in India, 97 (16), 161-172 (2017) 